\title{
Clinical Condition and Management of 114 Mamushi (Gloydius blomhoffii) Bites in a General Hospital in Japan
}

\author{
Takahito Chiba ${ }^{1}$, Hidenobu Koga ${ }^{1}$, Nanae Kimura ${ }^{1}$, Maho Murata ${ }^{1}$, Shunichi Jinnai ${ }^{1}$, \\ Asako Suenaga ${ }^{1}$, Futoshi Kohda ${ }^{1}$ and Masutaka Furue ${ }^{2}$
}

\begin{abstract}
:
Objective Mamushi (Gloydius blomhoffii) snakebite is the most common type of snake injury in Japan and is also seen in China and Korea. Although the components of Mamushi venom have been investigated, epidemiological and clinical descriptions still remain limited in the English literature. The aim of this study was to review the clinical features and management of patients with injuries related to Mamushi snakebites.

Methods We conducted a retrospective examination of 114 Mamushi snakebite cases encountered at a general hospital in Japan from January 2004 to November 2016. Data were collected from the medical records.

Results We found that Mamushi snakebites commonly occurred during summer and the daytime, with elderly men typically being affected. The symptom grade at initial consultation was significantly worse in the walk-in group than in the ambulance admission group, probably due to treatment delay. The number of fangs that pierced the skin was not related to the severity of the symptoms. The group treated with a tourniquet more frequently exhibited exacerbation of symptoms than those that received other treatments $(\mathrm{p}<0.001)$.

Conclusion The delay between patients being bitten and arriving at hospital as well as the number of fangs that pierced the skin did not affect the duration of hospitalization; however, proximal tourniquation should be avoided in such cases, as significant exacerbation of local symptoms was observed when this procedure was applied.
\end{abstract}

Key words: Mamushi, snakebite, injury, clinical feature, retrospective study

(Intern Med 57: 1075-1080, 2018)

(DOI: 10.2169/internalmedicine.9409-17)

\section{Introduction}

In Japan, venomous snakebites are mostly inflicted by three species: Mamushi (Gloydius blomhoffii), Habu (Protobothrops flavoviridis), and Yamakagashi (Rhabdophis tigrinus). Mamushi (Fig. 1) has a wide distribution in Japan as well as China and Korea (1). Inhabitants of rural areas or those working in fields in Japan have a higher chance of encountering Mamushi. In Japan, it has been reported that 1,000 cases of Mamushi bites occur annually, of which approximately $1 \%$ are fatal (2). Mamushi venom contains proteases, phospholipases, hyaluronidases, and other enzymes and induces local pain, erythema, and swelling at the bite site. It also includes hemorrhage factor-1 (HR1) or HR2, which causes very strong platelet aggregation, resulting in the development of wide ecchymosis and gastrointestinal bleeding (3). In cases with severe swelling, the serum levels of creatinine phosphokinase (CPK) are remarkably increased by rhabdomyolysis, which occasionally causes acute renal failure (2). Systemic administration of Mamushi antivenom treatment might be effective in bite victims $(4,5)$. However, reports on epidemiological and clinical analyses of Mamushi snakebites remain limited in the English literature.

Therefore, in this study, we retrospectively analyzed the demographic, clinical, and therapeutic aspects of 114 patients with Mamushi snakebites admitted to our hospital over a 13-year period.

${ }^{1}$ Department of Dermatology, Aso Iizuka Hospital, Japan and ${ }^{2}$ Department of Dermatology, Kyushu University School of Medicine, Japan Received: April 26, 2017; Accepted: August 29, 2017; Advance Publication by J-STAGE: December 27, 2017

Correspondence to Dr. Takahito Chiba, allheart@ dermatol.med.kyushu-u.ac.jp 


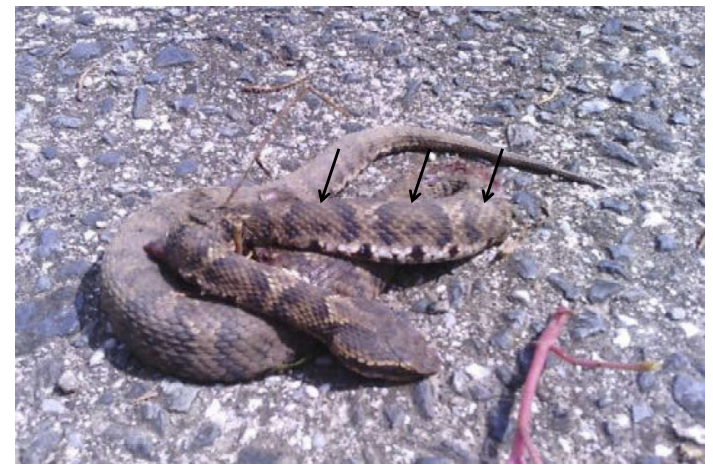

Figure 1. Mamushi (Gloydius blomhoffii). The characteristic pattern of hole coins (chains) on a Mamushi (arrows).

\section{Materials and Methods}

\section{Study population}

This is a retrospective study of 114 cases of Mamushi snakebites (January 2004 to November 2016), using data collected from inpatient case notes. All of these patients visited Aso Iizuka Hospital, which is one of the major general hospitals on Kyushu, the third largest and most southerly of the main islands of Japan. The study protocol was approved by the Ethics Committee of Aso Iizuka Hospital. Consent to publish and participate under the ethics, consent, and permissions in this study was also obtained from all patients.

\section{Patient diagnoses and treatments}

There are no reliable diagnostic biomarkers or methods for the diagnosis of Mamushi snakebites available in clinical practice, so this was performed by positive identification of the snake or observation of the clinical manifestations of envenomation (6) by two expert dermatologists. Monotherapy or combination therapies were performed using Mamushi antivenom horse serum (3) and/or cepharanthine (CEP), which has anti-inflammatory and anti-pain effects against snakebites (4). Antihistamines, antibiotics, and tetanus toxoid were administered in some cases. Patients with symptoms more severe than Grade III were administered antivenom serum.

\section{Records}

Demographic data, envenoming symptoms, serum level of CPK, length of hospital stay, and grade of severity of Mamushi snakebite symptoms were retrieved from clinical records. The symptom grade was evaluated using the classification method proposed by Hifumi et al. (2): Grade I, redness and swelling around the bitten area; Grade II, redness and swelling including the wrist or foot joint; Grade III, redness and swelling extending from the hand to the elbow or from the ankle to the knee; Grade IV, redness and swelling of the whole extremity; and Grade V, redness and swelling in parts beyond the extremity or systemic symptoms. Dete-
Table 1. Baseline Characteristics.

\begin{tabular}{|c|c|}
\hline Variable & n (\%), Median [IQR] \\
\hline Total number of patients & 114 \\
\hline Gender of patients, male/female (ratio) & $71 / 43(1.65: 1)$ \\
\hline Mean patient age, in years (range) & $57.2 \pm 23.0($ range: $2-91)$ \\
\hline \multicolumn{2}{|l|}{$\begin{array}{l}\text { Number and percentage of patients in } \\
\text { each of nine age ranges at time of ad- } \\
\text { mission, in years }\end{array}$} \\
\hline $0 \leq$ Age $\leq 9$ & $9(7.9)$ \\
\hline $10 \leq$ Age $\leq 19$ & $6(5.2)$ \\
\hline $20 \leq$ Age $\leq 29$ & $4(3.5)$ \\
\hline $30 \leq$ Age $\leq 39$ & $1(0.9)$ \\
\hline $40 \leq$ Age $\leq 49$ & $7(6.1)$ \\
\hline $50 \leq$ Age $\leq 59$ & $19(16.7)$ \\
\hline $60 \leq$ Age $\leq 69$ & $26(22.8)$ \\
\hline $70 \leq$ Age $\leq 79$ & $29(25.4)$ \\
\hline Age $\geq 80$ & $13(11.4)$ \\
\hline \multicolumn{2}{|l|}{ Year of admission } \\
\hline 2004 & $11(9.6)$ \\
\hline 2005 & $9(7.9)$ \\
\hline 2006 & $14(12.3)$ \\
\hline 2007 & $7(6.1)$ \\
\hline 2008 & $8(7.0)$ \\
\hline 2009 & $9(7.9)$ \\
\hline 2010 & $4(3.5)$ \\
\hline 2011 & $6(5.3)$ \\
\hline 2012 & $6(5.3)$ \\
\hline 2013 & $13(11.4)$ \\
\hline 2014 & $6(5.3)$ \\
\hline 2015 & $14(12.3)$ \\
\hline 2016 & $7(6.1)$ \\
\hline \multicolumn{2}{|l|}{ Bite location } \\
\hline Upper limb & $74(64.9)$ \\
\hline Lower limb & $40(35.1)$ \\
\hline \multicolumn{2}{|l|}{ The accident location of snake bite } \\
\hline Farm and rice field & $36(31.6)$ \\
\hline Yard & $34(29.8)$ \\
\hline Bush & $18(15.8)$ \\
\hline Riverside & $10(8.8)$ \\
\hline On the road & $9(7.9)$ \\
\hline Mountain area & $7(6.1)$ \\
\hline
\end{tabular}

rioration of symptoms during hospitalization by more than one grade was defined as "exacerbation."

\section{Statistical analyses}

Summary statistics of continuous variables are expressed as median (interquartile range: IQR), and categorical or ordinal variables are expressed as frequency (percentage). We analyzed categorical variables using Fisher's exact test and continuous variables using the Mann-Whitney U test. A oneway analysis of variance was used for the comparison of CPK levels among the different grades of symptoms due to Mamushi snakebites, while Scheffe's test was used for determining the significance of differences between groups. $p$ values are two-sided, with $\mathrm{p}<0.05$ considered to be statistically significant. All data were analyzed with the SAS statis- 
A
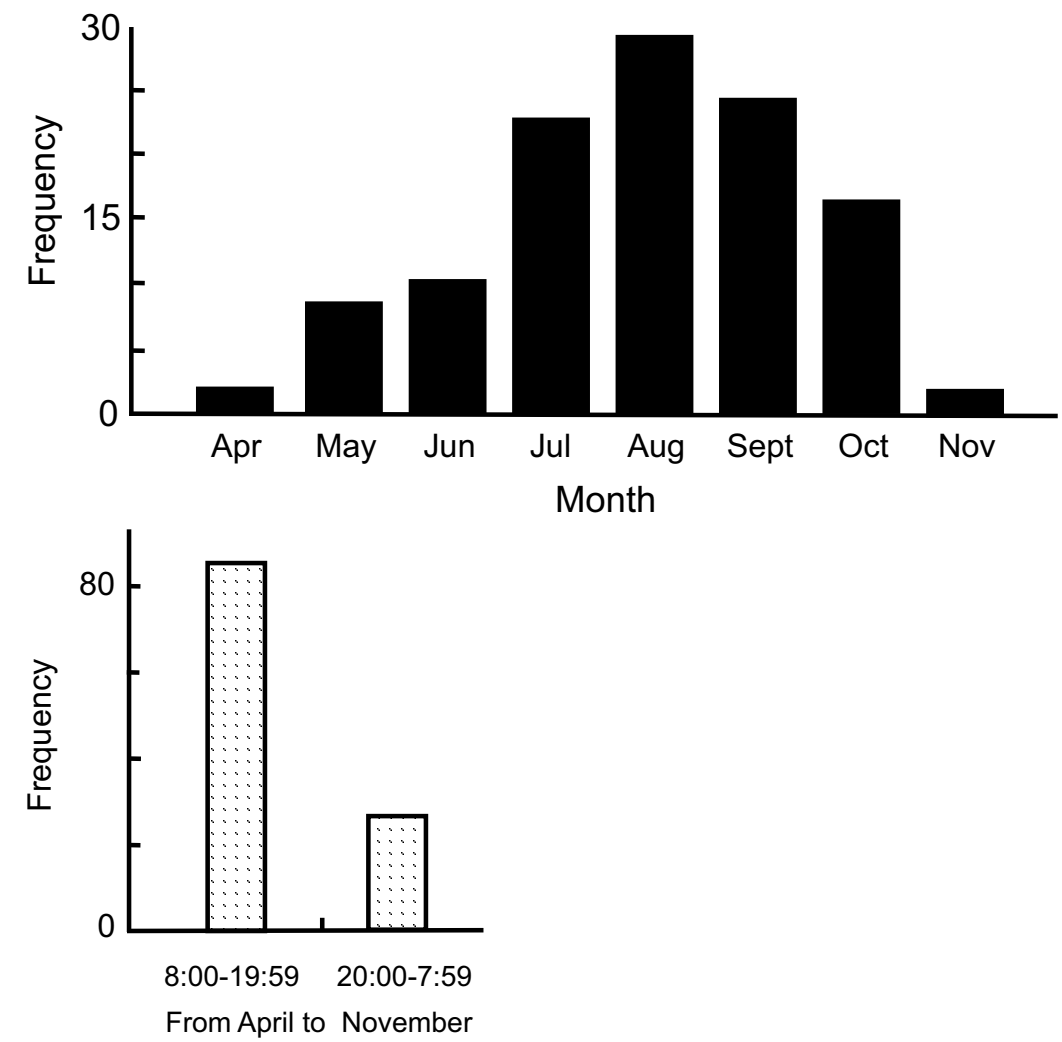

Figure 2. (A) The distribution of Mamushi snakebites in each month. (B) The association between the season and time of the day when Mamushi snakebites occur.

tical software program (version 9.4; SAS Institute, Cary, USA).

\section{Results}

\section{Baseline clinical characteristics}

The demographic characteristics of the patients and the circumstances of the snakebites are described in Table 1. The incidence was higher in males and in the elderly. The upper limbs were the most common site $(64.9 \%)$ of Mamushi snakebites, being affected almost twice as frequently as the lower limbs (35.1\%). The majority of patients were attacked by Mamushi in a farm, paddy field, or yard. Most of the snakebites occurred in the summer and early fall (between June and October) (Fig. 2A). In addition, approximately twice as many snakebites occurred in the daytime (08:00-19:59) as at night (20:00-07:59) in June to September. In contrast, in March, April, October, and November, daytime snakebites outnumbered nighttime ones by about five-fold (Fig. 2B).

\section{Symptoms and laboratory data}

As shown in Table 2, all patients complained of local tissue swelling at the bite site. The rates of polyopia and dizziness were $4.4 \%$ and $2.6 \%$, respectively, and there were no cases of cyanosis or coma. Regarding the grades of the symptoms, 21 of 114 patients had Grade I (18.4\%); 44 patients, Grade II (38.6\%); 37 patients, Grade III (32.5\%); 5 patients, Grade IV (4.4\%); and 4 patients, Grade V (3.5\%). In addition, the serum levels of CPK varied among the patients, 142.5 IU/L (IQR: 105.5-207.5), with significant elevation in Grade $\mathrm{V}$ patients (Table 2 and Fig. 3).

\section{Treatment and length of hospital stay}

In terms of the treatments, CEP monotherapy was applied in 31 patients $(27.2 \%)$, antivenom monotherapy in $5(4.4 \%)$, the combination of CEP and antivenom in $72(63.1 \%)$, and topical treatment only in $6(5.3 \%)$ (Table 2$)$. An adverse reaction to antivenom injection was recognized in 6 patients (5 cases of wheals and erythema and 1 case of anaphylactic reaction). The mean duration of hospitalization was 6.0 days (IQR: 3.0-8.0). No deaths caused by Mamushi snakebite were observed (Table 2).

\section{Stratified analyses between walk-in and ambulance admission groups}

We stratified the patients with regard to the admission type: walk-in admission $(\mathrm{n}=66)$, ambulance admission $(\mathrm{n}=$ $30)$, or unknown $(n=18)$. As shown in Table $3 \mathrm{~A}$, there were no remarkable differences among these groups in gender, deterioration of symptom grade during hospitalization, CPK level on admission, and duration of hospitalization. However, the symptom grade on admission was significantly worse in the walk-in group than in the ambulance group ( $\mathrm{p}<$ 0.006), suggesting that walk-in patients might have waited to receive a healthcare consultation, mistakenly thinking that they had been bitten by a non-venomous snake. 
Table 2. Clinical Features.

\begin{tabular}{lc}
\hline \multicolumn{1}{c}{ Variable } & $\mathrm{n}(\%)$, Median $[\mathrm{IQR}]$ \\
\hline Clinical manifestation & \\
Local swelling & $114(100)$ \\
Polyopia & $5(4.4)$ \\
Dizziness & $3(2.6)$ \\
Polypnoea & $1(0.9)$ \\
Grades of symptoms & \\
I & $21(18.4)$ \\
II & $44(38.6)$ \\
III & $37(32.5)$ \\
IV & $5(4.4)$ \\
V & $4(3.5)$ \\
Unknown & $3(2.6)$ \\
Laboratory data & \\
Creatinine phosphokinase (CPK) & $142.5[105.5-207.5]$ \\
Treatment & \\
Cepharanthine (CEP) alone & $31(27.2)$ \\
Anti-venom & $5(4.4)$ \\
Both CEP and anti-venom combination & $72(63.1)$ \\
Topical treatment only & $6(5.3)$ \\
Adverse effect of anti-venom & \\
Anaphylaxis & $1(0.9)$ \\
Wheal and erythema & $5(4.4)$ \\
Outcome & \\
Hospital death & $0(0)$ \\
Duration of hospital days & $6.0[3.0-8.0]$ \\
\hline &
\end{tabular}

\section{Stratified analyses by the number of bite marks}

Mamushi snakes have two venomous fangs. We speculated that the patients in whom both of these fangs had pierced the skin $(n=56)$ might show more severe symptoms than those in whom only one fang had penetrated $(n=22)$. However, this was not the case. There were no significant differences between these two groups in gender, symptom grade, deterioration of symptom grade during hospitalization, CPK level, or duration of hospitalization (Table 3B).

\section{Stratified analyses of cases with or without tourni- quet use}

It has traditionally been recommended that a tourniquet be applied proximal to the bite mark to prevent deterioration of the symptom grade by keeping the venom around the bite site. Our stratified analysis revealed that there were no significant differences in gender ratio or duration of hospitalization between the tourniquet $(n=62)$ and non-tourniquet groups $(\mathrm{n}=51)$. However, the tourniquet group had a worse clinical course, experiencing exacerbation of symptoms significantly more frequently than the non-tourniquet group (Table 3C).

\section{Discussion}

In the present study, the elderly were shown to be at an increased risk of Mamushi snakebites. This finding differs

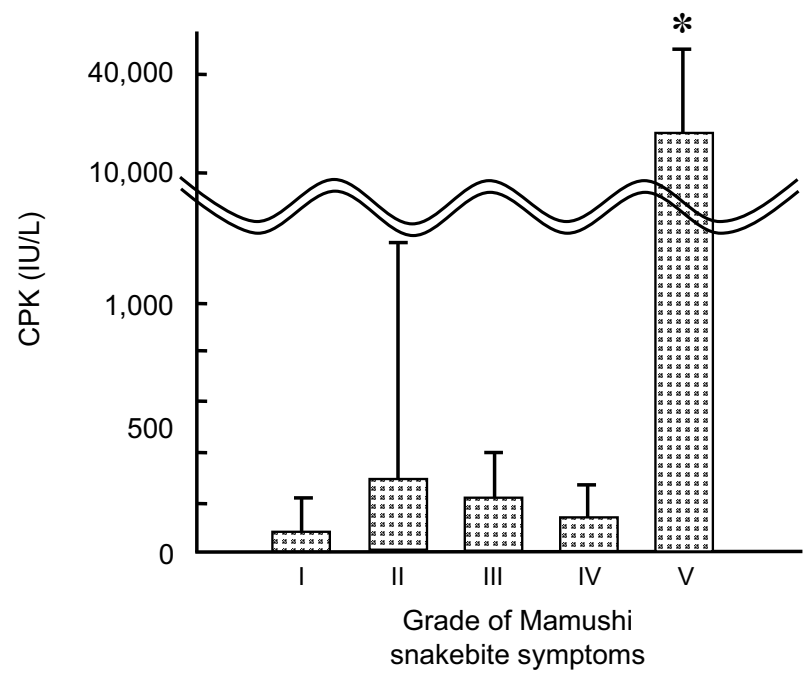

Figure 3. Creatine phosphokinase (CPK) levels for each grade of Mamushi snakebites on admission. Values are mean \pm SD $(\mathbf{n}=5)$. * $\mathbf{p}<0.05$ versus Grade I-IV groups (ANOVA).

from those in other countries, such as China, India, and Nepal $(7,8)$, probably due to differences in the agricultural sector and the age pyramid. Agriculture in Japan is dominated by the elderly, in contrast to other East Asian countries. The main season and time of the day when Mamushi snakebites occurred in this study were summer and the daytime, when the poikilothermal Mamushi snakes are more active (9).

Mamushi venom contains several types of enzymes, including proteases, phospholipases, and hyaluronidases (10-12). These enzymes spread through the lymphogenous pathway and induce local pain and swelling at the bite site. In cases of severe swelling, increases of CPK and blood myoglobin occur due to rhabdomyolysis $(2,13)$. None of the present cases suffering from Grade II or III local swelling and pain had elevated levels of CPK. A significant increase in CPK was detected only in the Grade V patients. These results suggest that local tissue swelling does not necessarily reflect muscle involvement.

It is well known that patients bitten by vipers should be treated at a hospital as soon as possible in order to achieve the best prognosis (14). As expected, in this study, the symptom grade was significantly less severe in the ambulance admission group than in the walk-in admission group. However, interestingly, there were no marked differences between these groups in the exacerbation rate, CPK level, and duration of hospitalization. This might mean that being administered an appropriate treatment is more important than the way in which a patient arrives at hospital.

Mamushi snakebites usually leave one or two very small wounds due to the insertion of fangs, which are $1 \mathrm{~cm}$ apart (3). We hypothesized that patients with two bite marks might have more severe symptoms than those with one because more venom might be injected in the former group. However, there were no significant differences in symptom severity between the two groups. In fact, it has been re- 
Table 3. Comparison of Various Characteristics N (\%), Median [IQR]. (A) A Comparison of the Clinical Characteristics between Ambulance Admission and Walk-in Groups. (B) A Comparison of the Clinical Characteristics Depending on the Number of Bite Marks. (C) A Comparison of the Clinical Characteristics between the Groups with and without Tourniquet Use during Hospitalization.

A.

\begin{tabular}{lcccc}
\hline \multicolumn{1}{c}{ Variable } & walk-in [n=66] & ambulance [n=30] & $\begin{array}{c}\text { Statistic } \\
\text { (Wilcoxon rank-sum test) }\end{array}$ & p value \\
\hline $\begin{array}{l}\text { Number } \\
\text { Sex (Female) }\end{array}$ & $25(37.9)$ & $10(33.3)$ & - & 0.820 \\
$\begin{array}{l}\text { More than Grade III } \\
\text { (on admission) }\end{array}$ & $33(51.6)$ & $6(20.7)$ & - & 0.006 \\
$\begin{array}{l}\text { Exacerbation } \\
\text { (in hospital) }\end{array}$ & $20(31.3)$ & $11(37.9)$ & - & 0.636 \\
$\begin{array}{l}\text { Creatinine kinase (U/L) } \\
\text { (on admission) }\end{array}$ & $135[92-207]$ & $157[115-208]$ & $1,590.5$ & 0.230 \\
Hospitalization & $6.0[4.0-8.0]$ & $5.5[3.0-7.0]$ & $1,371.0$ & 0.504 \\
\hline
\end{tabular}

B.

\begin{tabular}{|c|c|c|c|c|}
\hline Variable & One $[n=22]$ & two $[\mathrm{n}=56]$ & $\begin{array}{c}\text { Statistic } \\
\text { (Wilcoxon rank-sum test) }\end{array}$ & $\mathrm{p}$ value \\
\hline Number & & & - & - \\
\hline Sex (Female) & $9(40.99$ & $25(44.6)$ & - & 0.805 \\
\hline $\begin{array}{l}\text { More than Grade III } \\
\text { (on admission) }\end{array}$ & $8(36.4)$ & $23(42.6)$ & - & 0.798 \\
\hline $\begin{array}{l}\text { Exacerbation } \\
\text { (in hospital) }\end{array}$ & $6(27.3)$ & $19(35.2)$ & - & 0.597 \\
\hline $\begin{array}{l}\text { Creatinine kinase (U/L) } \\
\text { (on admission) }\end{array}$ & $141.5[92.0-164.0]$ & 133.0 [105.0-209.0] & 811.0 & 0.600 \\
\hline Hospitalization & $6.0[4.0-7.0]$ & $6.5[3.0-8.0]$ & 820.0 & 0.587 \\
\hline \multicolumn{5}{|l|}{ C. } \\
\hline Variable & tourniquet $[\mathrm{n}=62]$ & non-tourniquet $[\mathrm{n}=51]$ & $\begin{array}{c}\text { Statistic } \\
\text { (Wilcoxon rank-sum test) }\end{array}$ & $\mathrm{p}$ value \\
\hline Number & & & - & - \\
\hline Sex (Female) & $20(32.3)$ & $22(43.1)$ & - & 0.248 \\
\hline $\begin{array}{l}\text { Exacerbation } \\
\text { (in hospital) }\end{array}$ & $29(49.2)$ & $10(19.6)$ & - & 0.001 \\
\hline Hospitalization & $6.0[3.0-8.0]$ & $6.0[4.0-8.0]$ & $2,959.0$ & 0.765 \\
\hline
\end{tabular}

CPK: Creatine Phosphokinase

ported that up to four fang marks are observed in Mamushi bites (9), but snake venom is not always infused. The excretory pore of the Mamushi snake is far from the apical end of the fang, so $20 \%$ to $30 \%$ of bites are non-venomous (3).

The treatment of Mamushi bites is generally decided based on the grade of associated symptoms. At mild grades (I or II), patients are administered only CEP, even though it has not been definitively proven to provide a benefit. CEP has been reported to have biological membrane-stabilizing and anti-inflammatory effects without inducing adverse reactions in vivo (15). At severe grades (III-V), antivenom should be given, but its effectiveness remains controversial. Naito et al. reported that there were no marked differences between antivenom alone and CEP alone in terms of symptom progression in cases of Mamushi snakebites in Japan (16). For Grade I and II cases, no significant difference in the duration of hospital stay was identified between groups with antivenom alone and CEP alone (2). In contrast, Hifumi et al. showed that Grade III-V patients with antivenom treatment had a significantly shorter hospital stay than those without it (2). Thus, the standard treatment of Mamushi snakebites has recently involved both antivenom serum and CEP for patients in Japan with symptoms more severe than Grade III (17).

It is recommended that antivenom serum be administered intravenously just after premedication with hydrocortisone and/or antihistamine and/or epinephrine $(3,18)$. Premedication with antihistamine and epinephrine is expected to lower the risk of adverse effects by antivenom serum (19). At our hospital, both hydrocortisone and antihistamine are administered before antivenom serum injection. As additional traditional treatment, the use of a tourniquet has been believed to 
prolong the absorption of venom (20). However, the use of an arterial tourniquet or tying tourniquation with strings is not recommended in the treatment of Crotalus durissus snakebites because of the associated increase in potential adverse effects and the lack of evidence to support the efficacy of this approach (21-23). In the present study on Mamushi snakebites, proximal tourniquation significantly exacerbated the symptoms. In general, molecules with a molecular weight of less than $5 \mathrm{kDa}$ can pass through blood vessel walls; the molecular weight of Mamushi venom is 7-15 $\mathrm{kDa}(24,25)$. Thus, Mamushi venom is likely to be retained in the local tissue due to its difficulty diffusing into the blood circulation. Therefore, proximal tourniquation may prolong the retention of venom and increase tissue damage. In the guidelines on venomous snakebites proposed by the American Academy of Clinical Toxicology (AACT) and the European Association of Poison Centers and Clinical Toxicologists (EAPCCT), proximal tourniquation is not actually recommended for non-neurotoxic snakebites. Our data support this approach in the case of Mamushi bites.

The limitations of this study include its retrospective nature and the fact that the cases were from a single hospital, which limited the sample size and thus reduced the statistical power. However, we believe that this study is a useful review that will help emergency physicians who encounter cases of Mamushi snakebites and must decide on the initial treatment. A prospective multi-institutional study should nonetheless be performed to provide more complete epidemiological data on Mamushi snakebites in Japan.

The authors state that they have no Conflict of Interest (COI).

\section{References}

1. MacDiarmid RW, Campbell JA, Toure T. Snake Species of the World. In: A Taxonomic and Geographic Reference. v. 1. Herpetologists' League, Washington, D.C., 1999.

2. Hifumi T, Yamamoto A, Morokuma K, et al. Clinical efficacy of antivenom and cepharanthine for the treatment of Mamushi (Gloydius blomhoffii) bites in tertiary care centers in Japan. Jpn J Infect Dis 66: 26-31, 2013.

3. Hifumi T, Sakai A, Kondo Y, et al. Venomous snake bites: clinical diagnosis and treatment. J Intensive Care 3: 16, 2015.

4. Hifumi T, Yamamoto A, Morokuma K, et al. Surveillance of the clinical use of mamushi (Gloydius blomhoffii) antivenom in tertiary care centers in Japan. Jpn J Infect Dis 64: 373-376, 2011.

5. Fukuda T, Iwaki M, Hong SH, et al. Standardization of regional reference for mamushi (Gloydius blomhoffii) antivenom in Japan, Korea, and China. Jpn J Infect Dis 59: 20-24, 2006.

6. Gold BS, Dart RC, Barish RA. Bites of venomous snakes. N Engl J Med 347: 347-356, 2002.

7. Sharma SK, Chappuis F, Jha N, Bovier PA, Loutan L, Koirala S. Impact of snake bites and determinants of fatal outcomes in southeastern Nepal. Am J Trop Med Hyg 71: 234-238, 2004.

8. Thapar R, Darshan BB, Unnikrishnan B, et al. Clinicoepidemiological profile of snakebite cases admitted in a tertiary care centre in south India: a 5 years study. Toxicol Int 22: 66-70, 2015.

9. Sakai A. [Diagnosis and treatment of snakebite by Mamushi and Yamakagashi]. Chudoku Kenkyu (Jpn J Toxicol) 26: 193-199, 2013 (in Japanese).

10. Iwanaga S, Sato T, Mizushima Y, Suzuki T. Studies on snake venoms. XVII. Properties of the bradykinin releasing enzyme in the venom of Agkistrodon halys blomhoffii. J Biochem 58: 123-129, 1965.

11. Iwanaga S, Suzuki T. Characterization of the bradykinin releasing enzyme in the venom of Agkistrodon halys blomhoffii as salivary kallikrein of the snake. Hoppe Seylers Z Physiol Chem 349: 928929, 1968.

12. Kato H, Suzuki T. Structure of bradykinin-potentiating peptide containing tryptophan from the venom of Agkistrodon halys blomhoffii. Experientia 26: 1205-1206, 1970.

13. Masuoka N, Zhang J, Partoo L, et al. A new dipeptide, Ophosphoserylethanolamine isolated from Agkistroden blomhoffi (mamushi). Arch Biochem Biophys 407: 184-188, 2002.

14. Saravu K, Somavarapu V, Shastry AB, Kumar R. Clinical profile, species-specific severity grading, and outcome determinants of snake envenomation: an Indian tertiary care hospital-based prospective study. Indian J Crit Care Med 16: 187-192, 2012.

15. Nishino T, Katayama K, Takahashi Y, Tanaka T. Analysis of the experience in 32 cases of viper bites victims. Kyukyuigaku (Jpn J Acute Medicare) 37: 733-737, 2013 (in Japanese).

16. Naito $H$. Anti-venom requires for Mamushi bites? Nippon Iji Shinpo (Japan Med J) 3986: 24-27, 2000 (in Japanese).

17. Taki K, Ariyoshi K, Sakai J, Ishikawa H, Nakajima K, Endo Y. Analysis of viper bites by a national survey. J Jpn Soc Emer Med 17: $753-760,2014$

18. Miyagi Y. [Habu-bite]. Chudoku Kenkyu (Jpn J Toxicol) 20: 223233, 2007 (in Japanese).

19. Hifumi T, Sakai A, Yamamoto A, et al. Effect of antivenom therapy of Rhabdophis tigrinus (Yamakagashi snake) bites. J Intensive Care 2: 44, 2014.

20. Meggs WJ, Courtney C, O'Rourke D, Brewer KL. Pilot studies of pressure-immobilization bandages for rattlesnake envenomations. Clin Toxicol (Phila) 48: 61-63, 2010.

21. Watt G, Padre L, Tuazon ML, Theakston RD, Laughlin LW. Tourniquet application after cobra bite: delay in the onset of neurotoxicity and the dangers of sudden release. Am J Trop Med Hyg 38: 618-622, 1988

22. Pugh RN, Theakston RD. Fatality following use of a tourniquet after viper bite envenoming. Ann Trop Med Parasitol 81: 77-78, 1987.

23. Amaral CF, Campolina D, Dias MB, Bueno CM, Rezende NA. Tourniquet ineffectiveness to reduce the severity of envenoming after Crotalus durissus snake bite in Belo Horizonte, Minas Gerais, Brazil. Toxicon 36: 805-808, 1998.

24. Fujimi TJ, Kariya Y, Tsuchiya T, Tamiya T. Nucleotide sequence of phospholipase $\mathrm{A}(2)$ gene expressed in snake pancreas reveals the molecular evolution of toxic phospholipase A(2) genes. Gene 292: 225-231, 2002.

25. Fujimi TJ, Nakajyo T, Nishimura E, Ogura E, Tsuchiya T, Tamiya T. Molecular evolution and diversification of snake toxin genes, revealed by analysis of intron sequences. Gene 313: 111-118, 2003.

The Internal Medicine is an Open Access article distributed under the Creative Commons Attribution-NonCommercial-NoDerivatives 4.0 International License. To view the details of this license, please visit (https://creativecommons.org/licenses/ by-nc-nd/4.0/).

(C) 2018 The Japanese Society of Internal Medicine

Intern Med 57: 1075-1080, 2018 